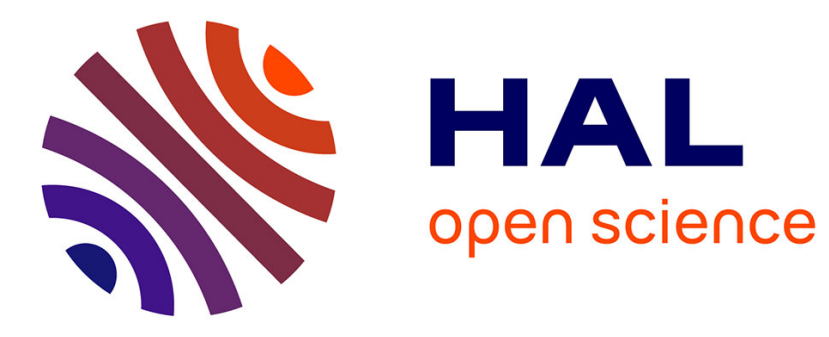

\title{
The promoting effect of pyridine ligands in the Pd-catalysed Heck-Matsuda reaction
}

\author{
Walid Khodja, Alexandre Leclair, Jordi Rull-Barrull, Francoise Zammattio, \\ Ksenia V. Kutonova, Marina E. Trusova, Francois-Xavier Felpin, Mireia \\ Rodriguez-Zubiri
}

\section{To cite this version:}

Walid Khodja, Alexandre Leclair, Jordi Rull-Barrull, Francoise Zammattio, Ksenia V. Kutonova, et al.. The promoting effect of pyridine ligands in the Pd-catalysed Heck-Matsuda reaction. New Journal of Chemistry, 2016, 40 (10), pp.8855-8862. 10.1039/c6nj01717g · hal-02141582

\section{HAL Id: hal-02141582 \\ https://hal.science/hal-02141582}

Submitted on 24 Feb 2021

HAL is a multi-disciplinary open access archive for the deposit and dissemination of scientific research documents, whether they are published or not. The documents may come from teaching and research institutions in France or abroad, or from public or private research centers.
L'archive ouverte pluridisciplinaire HAL, est destinée au dépôt et à la diffusion de documents scientifiques de niveau recherche, publiés ou non, émanant des établissements d'enseignement et de recherche français ou étrangers, des laboratoires publics ou privés. 


\title{
The promoting effect of pyridine ligands in the Pd-catalysed Heck- Matsuda reaction
}

\author{
Walid Khodja, ${ }^{[a],[b]}$ Alexandre Leclair, ${ }^{[a]}$ Jordi Rull-Barrull, ${ }^{[a]}$ Françoise Zammattio, ${ }^{[a]}$ Ksenia V. \\ Kutonova, ${ }^{[\mathrm{c}]}$ Marina E. Trusova,${ }^{[\mathrm{c}]}$ François-Xavier Felpin ${ }^{*[\mathrm{a}],[\mathrm{d}]}$ and Mireia Rodriguez-Zubiri ${ }^{*[\mathrm{a}]}$
}

\begin{abstract}
An efficient $\mathrm{Pd}$-catalyzed arylation reaction of challenging acyclic olefins, in the presence of an organic ligand, has been disclosed. Commercially available cheap pyridine-based ligands are able to promote good to excellent yields for poorly efficient Heck-Matsuda arylation reactions of several allylic alcohols. A wide range of electronically different arenediazonium salts bearing either electron-releasing or withdrawing groups have been used allowing the synthesis of a range of $\beta$-aryl-methoxy-lactols. The catalytic system has been optimised, along with the reaction conditions, in order to achieve remarkable yields in less than $1 \mathrm{~h}$.
\end{abstract}

Keywords: Heck-Matsuda reaction - Arenediazonium salts - Palladium • N-ligands • Allylic alcohols

\section{Introduction}

Heck-type transformations are unwaveringly essential tools used by organic chemists for the formation of carbon-carbon bonds with wide applications in fine chemistry and materials science for both academy and industry. ${ }^{1,2}$ The Heck-Matsuda counterpart of these palladium(0)catalyzed cross-coupling reactions using diazonium salts (Scheme 1) has emerged as an interesting alternative to alleviate several problems encountered with aryl halides. ${ }^{3-17}$

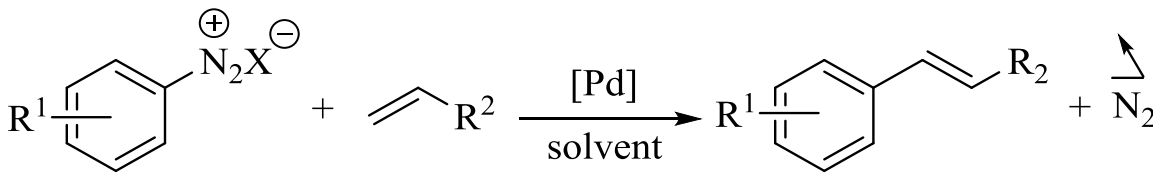

Scheme 1. General equation for the Heck-Matsuda reaction

Indeed, the use of arenediazonium salts allows very mild reaction conditions since the

[a] W. Khodja, A. Leclair, Dr F. Zammattio, Dr J. Rull-Barrull, Prof F.-X. Felpin* and Dr M. Rodriguez-Zubiri* UMR 6230 CEISAM; Université de Nantes; UFR des Sciences et des Techniques, CNRS

2 rue de la Houssinière, 44322 Nantes Cedex 3 , France

E-mail: mireia.rodriguez@univ-nantes.fr

[b] W. Khodja

Laboratoire de Chimie de Coordination CNRS (UPR 8241), BP 44099, 205 route de Narbonne, 31077

Toulouse cedex 4, France

[c] Dr K. V. Kutonova, Dr M. E. Trusova

Department of Biotechnology and Organic Chemistry, National Research Tomsk Polytechnic University, 43 Lenin ave., 634050 Tomsk, Russia

[d] Prof F.-X. Felpin

Institut Universitaire de France,

1 rue Descartes, 75231 Paris Cedex 5, France.

E-mail: fx.felpin@univ-nantes.fr 
palladium oxidative addition step is easily accessible due to the high reactivity of the nitrogen function. ${ }^{18}$ Once the $\mathrm{C}-\mathrm{N}_{2}{ }^{+}$bond has been dissociated by reaction with the $\mathrm{Pd}(0)$ precursor, the olefin insertion step takes place more easily on the resulting cationic palladium intermediate when compared to the classical Heck process. In addition, the hazardous reputation of diazonium salts has been mitigated and several safe industrial processes have been developed recently. ${ }^{19}$ Indeed, arenediazonium tetrafluoroborates, hexafluorophosphates and tosylates, among others, have revealed good solubility, high reactivity and, more importantly, they can be stable up to $600{ }^{\circ} \mathrm{C}$ and be handled safely on a large scale, as reported recently by Filimonov and co-workers. ${ }^{20-22}$

The large range of widely accessible and inexpensive anilines, and the ease of the diazotization strategy, have enabled the coupling of olefins with arenediazonium salts exhibiting very different steric and electronic properties. Although a substantial amount of substrates have been arylated, this strategy seems essentially limited to acrylates and styrenes. Other olefins, less prone to arylation in the presence of arenediazonium salts, represent an important challenge to be addressed. ${ }^{23,24}$ The reported inability to guide the regioselectivity of the $\beta$-hydride elimination and the migratory insertion step make the arylation of acyclic alkenes a challenging issue. ${ }^{25}$ In this area, the development of ligand-based catalytic systems could afford a step forward towards a convenient model process with a broad scope of application.

Palladium (II) species generated during the oxidative addition step exist in solution as coordination complexes weakly stabilized by coordinated solvent molecules and are prone to decomposition by formation of inactive Pd-black aggregates. Formal donation of one or more electron pairs from a chelating organic ligand generally involves stabilization of metal species. In spite of their usefulness in homogeneous catalysis, phosphanes have mostly been found unsuitable ligands for Pd-catalyzed Heck-Matsuda reactions, presumably because they are capable of transferring an electron to arenediazonium salts to form arene radicals. ${ }^{26}$ On the other hand, several N-containing ligands such as the thiourea of Yang et al., ${ }^{27}$ the carbenes of Song et al. ${ }^{28}$ and Beller and coworkers, ${ }^{29}$ and the macrocyclic triolefin of Roglans et al., ${ }^{30}$ have proven to be compatible with $\mathrm{Pd}$ for the arylation of highly reactive acrylates in the presence of diazonium salts, although the catalytic performance could not be substantially improved.

It has only recently been proven that chiral oxazoline-type ligands are effective in the intermolecular enantioselective Heck-Matsuda reaction and remarkable results have, in this way, been reported for the asymmetric arylation of several allylic alcohols. ${ }^{31-34}$

However, a careful outlook on the literature survey reveals the lack of a full study on the influence of an organic ligand in the catalytic activity of the Heck-Matsuda reaction so that the existing limitations, such as the arylation of resistant olefins, could find a valuable solution through a practical and efficient general protocol. It is thus of great interest to disclose cheaper organic ligands for non chiral arylation reactions.

With this in mind, we have attempted to develop simple and efficient catalytic systems containing $\mathrm{N}$-ligands for the arylation of acyclic alkenes. We have examined very common, commercially available, cheap and tunable pyridine-based ligands in the challenging arylation of allylic alcohols in the presence of a variety of arenediazonium salts. Our preliminary results towards this end are reported herein.

\section{Experimental Section}

\subsection{Instrumentation and materials}

All commercial reagents were used as received. Extra pure methanol and dichloromethane were used without further purification. Purification of products was carried out by flash column chromatography using silica gel $(40-30 \mu \mathrm{m})$. Analytical thin layer chromatography (TLC) was performed on $0.25 \mathrm{~mm}$ silica gel 
60-F254 plates. Visualization was accomplished with UV lamp $(254 \mathrm{~nm}) .{ }^{1} \mathrm{H}$ and ${ }^{13} \mathrm{C}$ NMR spectra were recorded at $300 \mathrm{MHz}$ and $75 \mathrm{MHz}$ respectively, and they are reported as $\delta$ values (ppm) relative to residual $\mathrm{CDCl}_{3} \delta \mathrm{H}(7.26 \mathrm{ppm}), \mathrm{CDCl}_{3} \delta \mathrm{C}(77.16 \mathrm{ppm})$ as internal standard. Low resolution mass spectroscopy (LRMS) was performed using chemical ionization $(\mathrm{Cl})$. High resolution mass spectroscopy (HRMS) was recorded on an orbitrap spectrometer. The GC analyses were performed on a GC-FID Agilent 7820A chromatograph equipped with a $30 \mathrm{~m}$ HP5 capillary column. The GC-MS analyses were recorded on a TRACE GC Ultra (ThermoScientific) apparatus equipped with a $30 \mathrm{~m}$ TR-5MS silica capillary column and a DSQII quadrupole analyser (ThermoScientific).

\subsection{Methods}

2.2.1. Arenediazonium tetrafluoroborate salts (general procedure): To a stirred solution of the corresponding substituted aniline $(23.4 \mathrm{mmol})$ in $\mathrm{Et}_{2} \mathrm{O}(4.6 \mathrm{~mL})$, was added an aqueous solution of tetrafluoroboric acid $(50 \%, 4.6 \mathrm{~mL}, 73.86 \mathrm{mmol})$ at $0{ }^{\circ} \mathrm{C}$. A solution of sodium nitrite $(1.64 \mathrm{~g}, 23.4 \mathrm{mmol})$ in water $(4.6 \mathrm{~mL})$ was then added dropwise at $0{ }^{\circ} \mathrm{C}$. The reaction was kept under vigorous stirring for further 30 minutes before filtration. The crude solid was washed with cold $\mathrm{EtOH}(10 \mathrm{~mL})$ and $\mathrm{Et}_{2} \mathrm{O}(3 \times 15$ $\mathrm{mL}$ ). The resulting white solid was dissolved in approximately $10 \mathrm{~mL}$ of acetone and re-precipated by adding $80 \mathrm{~mL}$ of $\mathrm{Et}_{2} \mathrm{O}$. After filtration, the resulting white solid $(65-85 \%$ yield) was dried under vacuum and kept in the fridge.

2.2.2. Pd-catalysed Heck-Matsuda reaction (general procedure): In a $25 \mathrm{~mL}$ pressure tube equipped with a magnetic stirring bar were sequentially added: $\mathrm{Pd}(\mathrm{TFA})_{2}(16.6 \mathrm{mg}, 0.05 \mathrm{mmol})$, pyridine-based ligands $(1 \mathrm{~mL}$ of a $\mathrm{MeOH}$ solution containing $0.11 \mathrm{mmol}$ for bidentate ligands or $0.22 \mathrm{mmol}$ for monodentate ligands) and methanol $(10 \mathrm{~mL})$. The reaction mixture was then heated $\left(60{ }^{\circ} \mathrm{C}\right)$ and kept under stirring for $5 \mathrm{~min}$. Next, base $(0.5 \mathrm{mmol})$, olefin $(1 \mathrm{~mL}$ of a $1 \mathrm{M} \mathrm{MeOH}$ solution, $1 \mathrm{mmol})$ and arenediazonium tetrafluoroborate $(2 \mathrm{mmol})$ were sequentially added to the reaction mixture. The suspension was kept under vigorous stirring at $60{ }^{\circ} \mathrm{C}$ for further $1 \mathrm{~h}$. The mixture was cooled and the solvent was removed under reduced pressure. The crude was purified (hexanes:ethyl acetate, 1:1, $6 \times 50$ $\mathrm{mL})$ through a plug of silica gel $(2.5 \times 3 \mathrm{~cm})$ and evaporated to dryness. The expected products along with other related isomers were identified by GC-MS and NMR techniques. All synthesised compounds are known and their characterisation data is according to the corresponding spectral data reported in the literature. ${ }^{32,35-39} n$-Dodecane and 1,2,4-trimethylbenzene or 1,3,5-trimethylbenzene were used as internal standards respectively for $\mathrm{GC}$ and ${ }^{1} \mathrm{H}$ NMR yield determination.

2.2.3. Pd-catalysed Heck-Matsuda reaction: kinetic study (general procedure): In a $25 \mathrm{~mL}$ pressure tube equipped with a magnetic stirring bar were sequentially added: $\mathrm{Pd}(\mathrm{TFA})_{2}(16.6 \mathrm{mg}, 0.05 \mathrm{mmol}), \mathbf{L} 5$ $(1 \mathrm{~mL}$ of a $0.11 \mathrm{M} \mathrm{MeOH}$ solution, $0.11 \mathrm{mmol})$ and methanol $(10 \mathrm{~mL})$. The reaction mixture was then heated (at $25^{\circ} \mathrm{C}, 40{ }^{\circ} \mathrm{C}$ or $60^{\circ} \mathrm{C}$ ) and kept under stirring for $5 \mathrm{~min}$. Next, $\mathrm{K}_{2} \mathrm{CO}_{3}(73 \mathrm{mg}, 0.5 \mathrm{mmol})$, 2butene-1,4-diol (1 mL of a $1 \mathrm{M} \mathrm{MeOH}$ solution, $1 \mathrm{mmol}$ ) and 4-chlorobenzenediazonium tetrafluoroborate (453 $\mathrm{mg}, 2 \mathrm{mmol}$ ) were sequentially added to the reaction mixture. The suspension was kept under vigorous stirring and several aliquots of the reaction mixture $(0.5 \mathrm{~mL})$ were sequentially extracted for analysis at different reaction times. Immediately after extraction and prior to GC analysis, the aliquots were quenched with $\mathrm{KCN}(0.5 \mathrm{~mL}$ of a $0.05 \mathrm{M} \mathrm{MeOH}$ solution, $0.025 \mathrm{mmol})$ and filtrated. The yields were determined by GC using $n$-dodecane as internal standard.

\section{Results and Discussion}

In this work we were led to study the Heck-Matsuda arylation of diol $\mathbf{1}$ with arenediazonium 2, as a model reaction, in the presence of a catalytic system made of $\operatorname{Pd}(\operatorname{TFA})_{2}$, a pyridine-based ligand and a base (Scheme 2). 


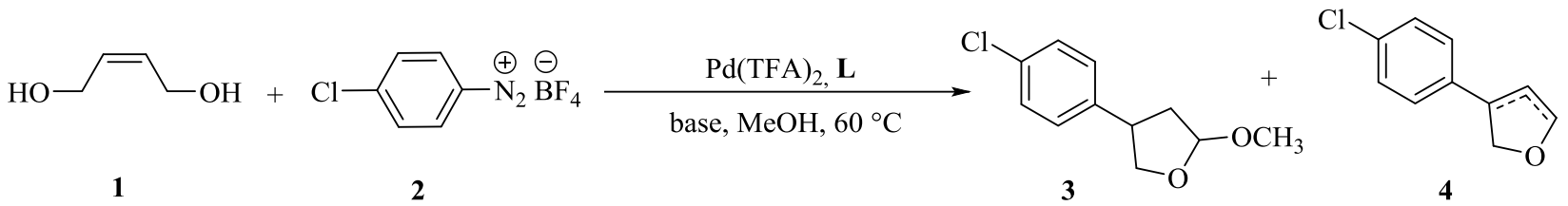

Scheme 2. Heck-Matsuda arylation of but-2-ene-1,4-diol, 1.

\subsection{Screening of Suitable Ligands}

Owing the very few existing reports on the use of ligands in the Heck-Matsuda reactions when compared to classical Heck transformations, our first experiments were aimed at evaluating the effect of an organic ligand on a model reaction (Scheme 2).

Interestingly, our study evidenced the essential role of an organic ligand since the already reported catalytic activity on the model reaction (Scheme 2$)$ was strongly inhibited $(<1 \%$ of coupling product 3 ) when using a ligand-free catalytic system whereas, keeping the same operational conditions ( $\mathrm{Pd}(\mathrm{TFA})_{2} 5 \mathrm{~mol} \%, \mathrm{ZnCO}_{3} 1 \mathrm{mmol}, 0.27 \mathrm{M}, 60{ }^{\circ} \mathrm{C}, 15 \mathrm{~min}$ ) but in the presence of a bis-oxazoline ligand, up to $93 \%$ yield of the expected product had been pointed out elsewhere. ${ }^{32}$

On the basis of these results we were prompt to conduct some studies to identify a compatible class of ligands able to afford good catalytic activities. We were led to investigate the effect of several classical and simple pyridine-type ligands (Figure 1) in terms of their chelating effect by means of the nature of the heteroatoms binding the metal and the size of the resulting metalligand chelate.<smiles>c1ccncc1</smiles>

L1<smiles>OCCc1ccccn1</smiles><smiles>C/C=C\C=C/C</smiles>

L5<smiles>c1ccc(-c2ccccn2)nc1</smiles>

L2<smiles>c1cnc2c(c1)ccc1cccnc12</smiles>

L3<smiles>Oc1ccccn1</smiles>

L6<smiles>c1ccc(COCc2ccccn2)cc1</smiles>

L7<smiles>Oc1cccc2cccnc12</smiles>

L8

Figure 1. Pyridine type ligands studied in this work: pyridine, L1; 2,2'-bipyridyl, L2; 1,10phenanthroline, L3; 2-hydroxyethylpyridine, L4; 2-hydroxymethylpyridine, L5; 2hydroxylpyridine, L6; 2-benzyloxymethylpyridine, L7 and 8-hydroxylquinoline, L8.

At first it should be recalled that, under our reaction conditions (depicted in Table 1) and in the absence of ligand, the corresponding arylation product 3 is produced in only $24 \%$ yield (entry 1 , Table 1). All the pyridine-based ligands studied have been shown to improve the efficiency of the catalytic process (entries 3, 4 and 6, Table 1) to the exception of L3, 1,10-phenanthroline, a very rigid bidentate ligand (entry 8 , Table1).

Table 1. Effect of pyridine type ligands in the efficiency of the arylation of diol $1 .^{[a]}$ 


\begin{tabular}{lcc}
\hline 1 & - & 24 \\
2 & L1 (4) & 0 \\
3 & L1 (2) & 56 \\
4 & L1 (1) & 42 \\
5 & L2 (2) & 0 \\
6 & L2 (1) & 35 \\
7 & L3 (2) & 0 \\
8 & L3 (1) & 20
\end{tabular}

[a] Reaction conditions: diol 1 ( $1 \mathrm{mmol})$, diazonium 2 ( $2 \mathrm{mmol}), \mathrm{K}_{2} \mathrm{CO}_{3}(0.5 \mathrm{mmol}), \operatorname{Pd}(\mathrm{TFA})_{2}(5 \mathrm{~mol} \%)$, ligand $(1,2$ or 4 equiv./Pd), $12 \mathrm{~mL} \mathrm{MeOH}, 60^{\circ} \mathrm{C}, 1 \mathrm{~h}$. [b] Determined by GC analysis using $n$-dodecane as internal standard.

Results from Table 1 have revealed several important features. Indeed, simple monodentate pyridine L1 has appeared as an efficient ligand affording 56\% of arylated products (entry 3 , Table 1). Increasing structural rigidity through the chelating ability seems, nevertheless, to have a detrimental effect on the catalytic efficiency since bipyridine, L2, and phenanthroline, L3, ligands are less performant than L1 (entries 6 and 8, Table 1). As expected, a ligand ratio L/Pd $=2$ was the optimal ratio found for monodentate ligands such as L1 (entry 3, Table 1), and L/Pd $=1$ for bidentate ligands L2 and L3 (entries 6 and 8, Table 1), so the active palladium species are stabilized by coordination of two pyridine nitrogen atoms to the metal center while keeping two free coordination sites for the catalytic reaction to take place. Consequently, 4 equiv. of monodentate L1 (entry 2, Table 1) and 2 equiv. of bidentate L2 and L3 (entries 2, 5 and 7, Table 1) inhibit completely the reaction as the coordination sphere of the palladium center becomes completely saturated with four $\sigma$-donor/ $\pi$-acceptor pyridine ligands, indicating, moreover, that the pyridine nitrogen atom seems to be a compatible and robust ligand for palladium under the studied reaction conditions.

The selectivity of the reaction is also an important issue to be addressed here since the expected arylation product $\mathbf{3}$ was often produced along with $\mathbf{4}$, an unprecedented arylated product which has been identified, on the basis of a GC-MS analysis, as an aryl dihydrofuran (Scheme 3). Due to its instability, the latter could not be isolated preventing us from its NMR characterization and yield quantification. Product 4 may correspond to the elimination product either from the acetal $\mathbf{3}$ or the lactol $\mathbf{5}$, precursor of $\mathbf{3}$ (Scheme 3). Formation of $\mathbf{4}$ could have been catalyzed by $\mathrm{HBF}_{4}$ formed as a byproduct of the $\mathrm{C}-\mathrm{C}$ bond formation reaction under the thermal reaction conditions used $\left(60^{\circ} \mathrm{C}\right)$. 

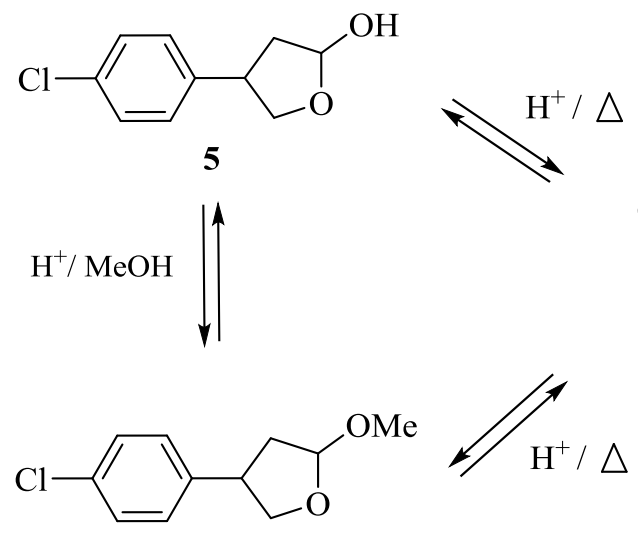<smiles>Clc1ccc(C2=CCOC2)cc1</smiles>

4

Scheme 3. Formation of $\mathbf{4}$ by elimination reaction from either $\mathbf{3}$ or $\mathbf{5}$.

Although the expected arylated compound $\mathbf{3}$ is the major product of the reaction, the formation of $\mathbf{4}$ is also enhanced by the use of a promoting ligand and could represent up to $20-30 \%$ of the total yield when using pyridine ligands.

Motivated by our results on the pyridine ligand $\mathbf{L} 1$ and conscious of the need to further develop it in order to tune its structural and electronic properties, we have also preliminary explored a family of pyridine type ligands bearing a second harder coordinating oxygen heteroatom. Indeed, hybrid chelating ligands containing at least two chemical groups such as a soft and a hard donor atoms have been of great interest. Amongst them, heterodentate hemilable ligands with a reversible labile functionality and an irreplaceable group have shown very interesting catalytic performances. Nitrogen and oxygen containing ligands are an important class of hemilabile mixed ligands. The $\pi$-acceptor character of the ( $\sigma$-donor) pyridine moiety can stabilize the metal centre in a low-oxidation state and the $(\sigma / \pi)$-donor ability of the oxygen renders the metal more susceptible to oxidative addition reactions. A series of $\mathrm{N}-\mathrm{O}$ ligands, L4L8 (Figure 1), which were assumed to be compatible with arenediazonium salts due to their reduced Lewis basicity compared to phosphine ligands, were thus studied (Table 2).

Table 2. Effect of pyridine-based ligands in the efficiency of the arylation of diol $1 .^{[a]}$

\begin{tabular}{ccc}
\hline Entry & Ligand (equiv.) & Yield $^{[\mathrm{b}]}$ [\%] product 3 \\
\hline 1 & - & 24 \\
2 & L4 (2) & 46 \\
3 & L4 (1) & 44 \\
4 & L5 (2) & 84 \\
5 & L5 (1) & 61 \\
6 & L6 (2) & 44 \\
7 & L6 (1) & 48 \\
8 & L7 (2) & 50 \\
9 & L7 (1) & 46 \\
10 & L8 (2) & 0 \\
11 & L8 (1) & 24 \\
\hline
\end{tabular}


[a] Reaction conditions: diol 1 ( $1 \mathrm{mmol})$, diazonium 2 (2 mmol), $\mathrm{K}_{2} \mathrm{CO}_{3}(0.5 \mathrm{mmol}), \mathrm{Pd}(\mathrm{TFA})_{2}(5 \mathrm{~mol} \%)$, ligand (1 or 2 equiv./Pd), $12 \mathrm{~mL} \mathrm{MeOH}, 60^{\circ} \mathrm{C}, 1 \mathrm{~h}$. [b] Determined by $\mathrm{GC}$ analysis using $n$-dodecane as internal standard.

Gratifyingly, the N,O-pyridine ligands studied promoted the formation of the Heck adduct 3 (entries 2-9, Table 2) to the exception of ligand L8 (entries 10-11, Table 2). This hydroxyquinoline can exists as its tautomeric form by intermolecular proton transfer (Scheme 4), ${ }^{40}$ and be deprotonated by the carbonate base present in the reaction media.<smiles></smiles>

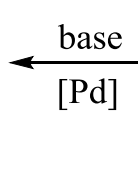<smiles>Oc1cccc2cccnc12</smiles><smiles></smiles><smiles>[O-]c1cccc2cccnc12</smiles>

$\mathbf{L 8}$

Scheme 4. Tautomeric pair from L8, 8-hydroxyquinoline, and their deprotonated analogues.

Ligand $\mathbf{L} \mathbf{8}$ could, in this way, behave as a rigid bidentate $\pi$-acceptor ligand through the $\mathrm{N} s p^{2}$ atom, and as a $\sigma$-donor through the $\mathrm{O}^{-}$function. The rigid structure of the quinoline backbone ligand does not presumably allow the $\mathrm{O}^{-}$function to decoordinate so that the use of two equivalents of L8 results in a complete inhibition of the catalytic activity (entry 10, Table 2) by the formation of a stable non labile square planar $\mathrm{Pd}$ complex with a saturated coordination sphere.

More importantly, a remarkable efficiency and selectivity towards the desired arylated product 3 was achieved using L5, 2-hydroxymethylpyridine (entry 4, Table 2). Indeed, 84\% yield and 94\% selectivity towards the formation of the expected methoxy lactol 3 was successfully attained with L5, whereas the other N,O-pyridine ligands (L4, L6 and L7) afforded up to $60 \%$ of arylated product 3 (entries 2-3 and 6-9, Table 2) and approximately up to $20 \%$ of 4 . A careful look at the experimental results and the structural features of these N,O-mixed ligands suggests that ligands able to form six-membered metal chelates may induce an increase in the reaction rate and that the participation of a free hydroxyl group in the catalytic cycle is not mandatory. We postulate that with shorter or longer tailored alkoxy substituents, the resulting metal-ligand chelates should be less stable and more prone to decomposition resulting in lower yields of arylated products.

Surprisingly, L5 was the only ligand for which 2 equivalents (respect to Pd) proved to be more efficient than a ratio $\mathrm{L} / \mathrm{Pd}=1$ (entries $4-5$, Table 2 ).

A detailed overview on the literature survey concerning L5, 2-hydroxymethylpyridine, ${ }^{41-44}$ and its coordination chemistry towards palladium and platinum metal precursors, has revealed the ability of this pyridine ligand to bind the metal center either as a mixed L,L- or L,X-type ligand (Figure 2), depending on the reaction conditions. However, only in the presence of a strong base (i.e. $\mathrm{KOH}$ or $\mathrm{NaH}$ ) the hydroxyl function is deprotonated and 2-pyridinemethanolate acts as a bidentate ligand towards a palladium center through a dative bond with the pyridine nitrogen atom, and a covalent bond with the alkoxy function (Figure 2a). ${ }^{41,45}$ We speculate that in the absence of a sufficiently strong base ( $\mathrm{pKa}$ of $\mathrm{K}_{2} \mathrm{CO}_{3}=10$ ), $\mathbf{L} 5$ ( $\mathrm{pKa}$ of $\mathrm{ROH}=16-20$ ) should remain protonated and establish two dative bonds with the metal: a stronger one owing the $\pi$-acceptor ability of the $\mathrm{N} s p^{2}$ atom, and a labile one with the lone pair of the $\mathrm{O}$ atom (Figure 2b). 
<smiles></smiles>

a) L,X-type ligand<smiles></smiles>

b) L,L-type ligand

Figure 2. Mixed L,X- or L,L-type ligand.

Another hypothesis on the coordination behavior of $\mathbf{L 5}$ concerns the formation of transition metal complex containing two L5 ligands where the square planar palladium complex is stabilized by two strongly coordinated pyridine moieties and two labile hydroxyl functions (Scheme 5) which may be able to dissociate from the metal center to the approach of the substrates.
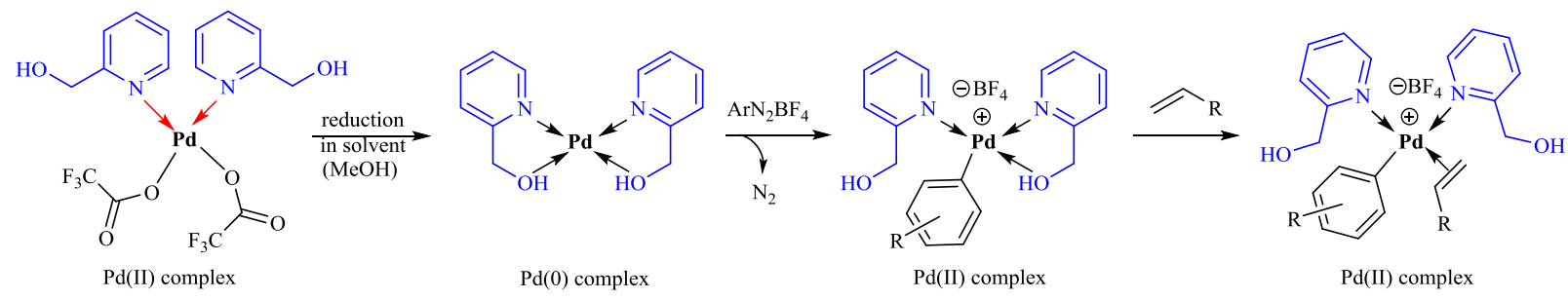

Scheme 5. Postulated $\mathrm{Pd}(\mathrm{II})$ and $\mathrm{Pd}(0)$ complexes with L5.

In order to gain insight on the factors governing the efficiency and selectivity of the studied catalytic systems, coordination studies with the $\operatorname{Pd}(T F A)_{2}$ metal precursor and 2hydroxymethylpyridine, L5, as the selected ligand owning its remarkable catalytic performance, are currently ongoing.

\section{2. $\quad$ Optimisation studies}

With the above presented notable results in hand, we looked for the optimal reaction conditions.

Typically, catalytic runs were conducted using the reaction conditions depicted in Table 2 unless specified.

Our optimisation studies revealed that in the absence of a palladium precursor, no Heck adducts were detected (entry 1 , Table 3 ).

Table 3. Efficiency of several palladium precursors in the arylation of diol 1. ${ }^{[a]}$

\begin{tabular}{ccc}
\hline Entry & {$[\mathrm{Pd}]$} & Yield $^{[\mathrm{b}]}[\%]$ product 3 \\
\hline 1 & - & 0 \\
2 & $\mathrm{~K}_{2} \mathrm{PdCl}_{4}$ & 0 \\
3 & $\mathrm{Pd}(\mathrm{dba})_{2}$ & 59 \\
4 & {$\left[\mathrm{Pd}\left(\mathrm{CH}_{3} \mathrm{CN}\right)_{4}\right]\left(\mathrm{BF}_{4}\right)_{2}$} & 64 \\
5 & $\mathrm{Pd}(\mathrm{OAc})_{2}$ & 64
\end{tabular}




\begin{tabular}{ccc}
6 & $\operatorname{Pd}(\text { TFA })_{2}$ & 84 \\
7 & $\operatorname{Pd}(\text { TFA })_{2}$ & $24^{[\mathrm{c}]}$ \\
\hline
\end{tabular}

[a] Reaction conditions: diol 1 (1 mmol), diazonium 2 (2 mmol), $\mathrm{K}_{2} \mathrm{CO}_{3}(0,5 \mathrm{mmol})$, [Pd] (5 mol\%), L5 (2 equiv./Pd), 12 $\mathrm{mL} \mathrm{MeOH}, 60^{\circ} \mathrm{C}, 1 \mathrm{~h}$. [b] Determined by GC analysis using $n$-dodecane as internal standard. [c] Pd(TFA) $)_{2} 1 \mathrm{~mol} \%$.

In the presence of $\mathbf{L 5}$, the best palladium precursor was found to be $\operatorname{Pd}(\operatorname{TFA})_{2}$ (entry 6 , Table 3). Replacement of $\operatorname{Pd}(T F A)_{2}$ by several other classical palladium $\operatorname{Pd}(0)$ and neutral or cationic $\mathrm{Pd}(\mathrm{II})$ precursors had a detrimental effect on the chemical yield values, although they remained significantly good (entries 3-5, Table 3). The selectivity performance was substantially the same for all the metal precursors studied. Even so, the use of $\mathrm{K}_{2} \mathrm{PdCl}_{4}$ proved ineffective (entry 2, Table 3).

It is worth pointing out that decreasing the catalyst loading to $1 \%$ led to a lower yield: $24 \%$ of product 3 exclusively (entry 7 , Table 3 ).

We next proceeded to explore the already known accelerating effect of several type of organic and inorganic bases in the Heck-Matsuda reaction (Table 4). Control experiments have revealed that the use of a base appears essential since only $13 \%$ yield was obtained without any base (entry 1 , Table 4 ).

Table 4 illustrates our results on screening different organic and inorganic bases. $\mathrm{K}_{2} \mathrm{CO}_{3}$ allowed compound 3 with the best yield and selectivity. Replacing $\mathrm{K}_{2} \mathrm{CO}_{3}$ for $\mathrm{ZnCO} \mathrm{Cs}_{2} \mathrm{CO}_{3}$, $\mathrm{CaCO}_{3}$ or AcONa was detrimental for the process affording lower chemical yields (entries 2-4 and 6, Table 4). Instead, 2,6-di-tert-butyl-4-methylpyridine (DTBMP) allowed high yields but also higher amounts of $4(>10 \%)$. On the other hand, sodium citrate, an organic base bearing three carboxylate functions, afforded a catalytic performance equivalent to $\mathrm{K}_{2} \mathrm{CO}_{3}$, with only a marginally lower catalytic selectivity (entry 8 , Table 4). Due to its efficiency, selectivity, low cost, and absence of metal counterion, $\mathrm{K}_{2} \mathrm{CO}_{3}$ represented an interesting base allowing better results than the other classical candidates studied.

Table 4. Efficiency of several bases in the arylation of diol 1. ${ }^{[a]}$

\begin{tabular}{ccc}
\hline Entry & Base & Yield $^{[\text {b] }}[\%]$ product 3 \\
\hline 1 & - & 13 \\
2 & $\mathrm{CaCO}_{3}$ & 44 \\
3 & $\mathrm{Cs}_{2} \mathrm{CO}_{3}$ & 49 \\
4 & $\mathrm{ZnCO}_{3}$ & 65 \\
5 & $\mathrm{~K}_{2} \mathrm{CO}_{3}$ & 84 \\
6 & $\mathrm{AcONa}$ & 55 \\
7 & DTBMP & 74 \\
8 & Sodium citrate & 80 \\
\hline
\end{tabular}

[a] Reaction conditions: diol 1 ( $1 \mathrm{mmol})$, diazonium 2 (2 mmol), base $(0,5 \mathrm{mmol}), \operatorname{Pd}(\mathrm{TFA})_{2}(5 \mathrm{~mol} \%)$, L5 (2 equiv./Pd), $12 \mathrm{~mL} \mathrm{MeOH}, 60^{\circ} \mathrm{C}, 1 \mathrm{~h}$. [b] Determined by GC analysis using $n$-dodecane as internal standard.

Owing its high polarity, its capability to reduce $\mathrm{Pd}(\mathrm{II})$ to $\mathrm{Pd}(0)$ in the reaction media, and its green properties when compared to other organic solvents, ${ }^{46,}{ }^{47} \mathrm{MeOH}$ was considered the solvent of choice for the Heck-Matsuda reaction studied. The highest catalytic activity was observed at $0.08 \mathrm{M}$ (entry 4 , Table 2 ) reaction concentration. Lower concentrations did not have a strong impact on the reaction effectiveness and/or selectivity $(0.07 \mathrm{M}, 76 \%$ yield). However, at higher concentrations, a detrimental effect on the catalytic efficiency $(68 \%$ yield at $0.1 \mathrm{M}$ and $35 \%$ yield at $0.4 \mathrm{M}$ ) was observed, presumably due to the limited solubility of the diazonium salts in the reaction solvent. 


\subsection{Kinetics studies}

One question that still needed to be addressed in order to conclude our optimization studies was the effect of the reaction time and the temperature on the efficiency of the studied process. The $\mathrm{Pd}(\mathrm{TFA})_{2}$ catalyst was already shown to deposit inactive metallic $\mathrm{Pd}$ at high temperatures and/or long reaction times in protic polar solvents. We have therefore deeply investigated our catalytic system by monitoring the reaction at different temperatures. Once more, catalytic runs were conducted using the reaction conditions shown in Table 2, in the presence of L5, but at different temperatures as specified.

As depicted in Figure 3, temperature plays an important role in the kinetics of the reaction. As expected, decreasing the temperature results in a decrease of the reaction rate since longer reaction times are needed to achieve quantitative yields of arylated product 3.

For all conducted experiments, product 4 was detected (along with compound 3) but represented less than $5 \%$ of the total yield and decreased to $0 \%$ as the amount of product 3 approached quantitative yields, suggesting an evolution of 4 to 3 , presumably by $\mathrm{MeOH}$ electrophilic addition to the double bond under acidic $\left(\mathrm{HBF}_{4}\right)$ conditions.

Our set of results have shown that decreasing the reaction temperature from $60^{\circ} \mathrm{C}$ to $40{ }^{\circ} \mathrm{C}$ led to reaction times $\times 2$ longer, and rates $\times 5$ slower were recorded when performing the same reaction at room temperature $\left(25^{\circ} \mathrm{C}\right)$. Thus, high yields for product 3 were afforded in only $1 \mathrm{~h}$ at $60{ }^{\circ} \mathrm{C}$, in $4 \mathrm{~h}$ at $40^{\circ} \mathrm{C}$ and in $48 \mathrm{~h}$ at $25^{\circ} \mathrm{C}$.

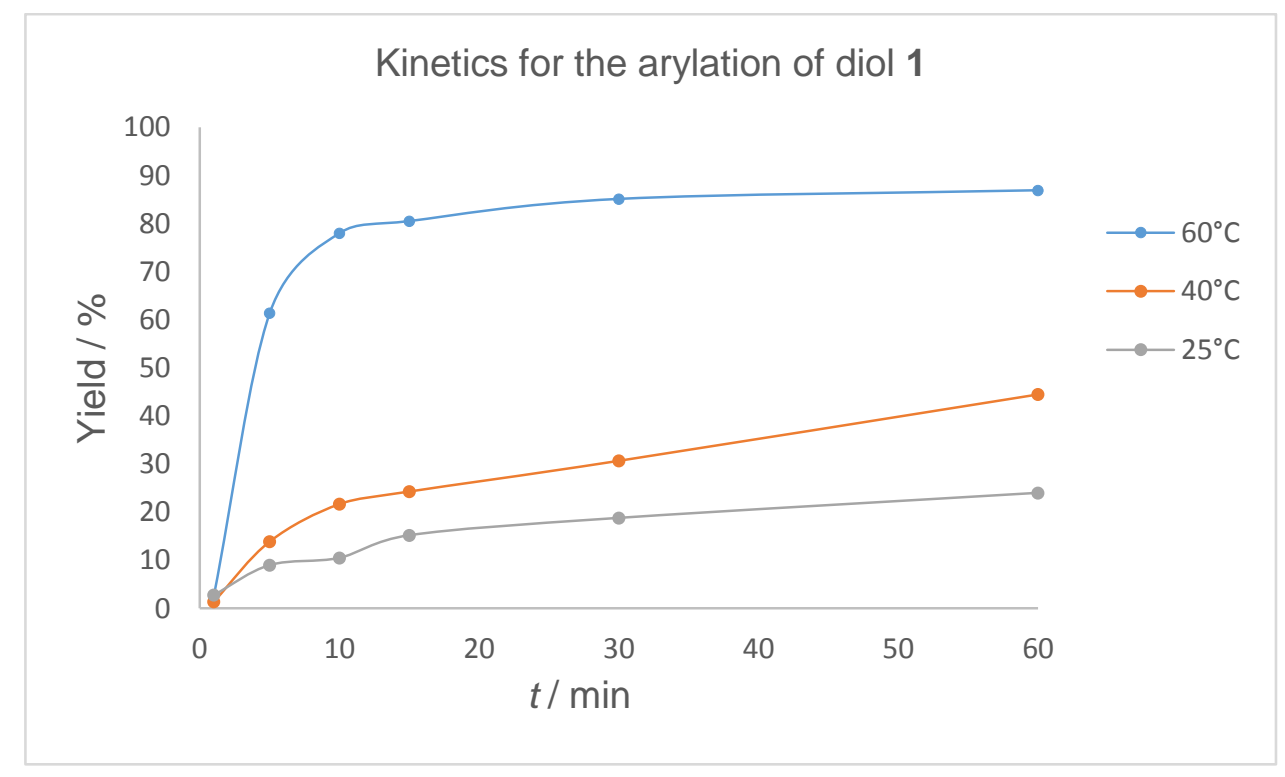

Figure 3. Representation of the kinetics up to $1 \mathrm{~h}$ at $25^{\circ} \mathrm{C}, 40^{\circ} \mathrm{C}$ and $60^{\circ} \mathrm{C}$, for the formation of arylated product $\mathbf{3}$ in the presence of $\mathbf{L 5}$.

More interestingly, we evaluated the effect of our selected ligand L5 on the kinetics of the studied reaction by monitoring, in a similar manner, the evolution of the coupling reaction but in the absence of any ligand. In the absence of L5, only $4 \%\left(25^{\circ} \mathrm{C}\right), 8 \%\left(40^{\circ} \mathrm{C}\right)$ and $18 \%\left(60{ }^{\circ} \mathrm{C}\right)$ of 3 was obtained indicating that the reaction proceeded with very slow kinetics without any organic ligand. These latter results confirmed the usefulness of 2-hydroxymethylpyridine, L5, for the arylation of acyclic allylic alcohols with arenediazonium salts.

\subsection{Scope of the reaction}


To assess the synthetic potential of the newly disclosed catalytic system, its efficiency was evaluated in the arylation of diol 1 (Scheme 2) towards different arenediazonium salts containing electron releasing or electron withdrawing groups (Table 5).

Table 5. Scope of the Heck-Matsuda arylation of diol $\mathbf{1}$ using L5. ${ }^{\text {[a] }}$

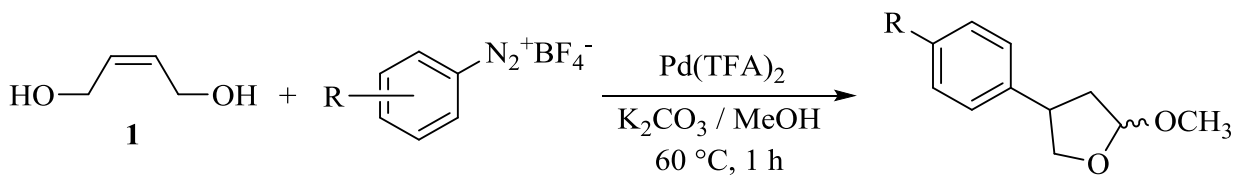

Entry Ligand (equiv.)

[a] Reaction conditions: diol 1 ( $1 \mathrm{mmol})$, diazonium (2 mmol), $\mathrm{K}_{2} \mathrm{CO}_{3}(0,5 \mathrm{mmol}), \mathrm{Pd}(\mathrm{TFA})_{2}(5 \mathrm{~mol} \%), 12 \mathrm{~mL} \mathrm{MeOH}$, $60^{\circ} \mathrm{C}, 1 \mathrm{~h}$. [b] Determined by GC analysis. [c] Determined by ${ }_{1} \mathrm{H}$ NMR analysis using either $1,2,4$-trimethylbenzene or 1,3,5-trimethylbenzene as internal standard. 
As already shown, yields were greatly enhanced when using diazonium salts bearing a chloro function (entries 1-2, Table 5). Remarkably, submission of diol 1 to coupling with electron rich diazonium salts in the presence of L5 (entries 3-4, 7-8, Table 5) gave also good to excellent results. As expected, the reaction was less improved by the use of $\mathbf{L} \mathbf{5}$ in the presence of highly electron poor diazonium salts bearing a nitro group (entries 5-6, Table 5), presumably due to their enhanced electrophilic character and, thus, greater reactivity towards a nucleophilic palladium.

We next studied the effect of $\mathbf{L} \mathbf{5}$ on the Heck-Matsuda arylation of other allylic alcohols towards diazonium 2. The results (Table 6) have shown that the protocol adopted for the arylation of diol 1 proved compatible with other substrates since the presence of $\mathbf{L 5}$ provoked up to $\mathbf{5 0 \%}$ improvement of the initial yields obtained without ligand for the arylation of pent-3-en-2-ol (entries 1-2, Table 6).

To the best of our knowledge, our results represent the first example of the Heck-Matsuda arylation of cyclohex-2-en-1-ol with yields up to $82 \%$ (entries 3-4, Table 6).

Table 6. Scope of the Heck-Matsuda arylation reaction using L5. ${ }^{\text {[a] }}$

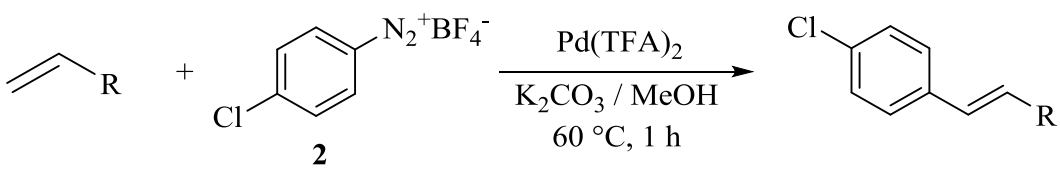

\begin{tabular}{|c|c|c|c|c|c|}
\hline Entry & $\begin{array}{l}\text { Ligand } \\
\text { (equiv.) }\end{array}$ & Olefin & Product & Yield $^{\mathrm{b}}[\%]$ & $\begin{array}{c}\text { Total Yield }^{\text {b }} \\
{[\%]}\end{array}$ \\
\hline 1 & - & & & & 0 \\
\hline 2 & L5 (2) & & & & 49 \\
\hline 3 & - & & & & 0 \\
\hline \multirow{3}{*}{4} & & & & 51 & \\
\hline & L5 (2) & & $\mathrm{Cl}^{-}$ & & 82 \\
\hline & & & & 31 & \\
\hline
\end{tabular}

[a] Reaction conditions: olefin (1 mmol), diazonium 2 (2 mmol), $\mathrm{K}_{2} \mathrm{CO}_{3}(0,5 \mathrm{mmol}), \mathrm{Pd}(\mathrm{TFA})_{2}(5 \mathrm{~mol} \%), 12 \mathrm{~mL} \mathrm{MeOH}$, $60^{\circ} \mathrm{C}, 1 \mathrm{~h}$. [b] Determined by ${ }^{1} \mathrm{H}$ NMR analysis using either $1,2,4$-trimethylbenzene or $1,3,5$-trimethylbenzene as internal standard. 


\section{Conclusions}

In summary, the association of $\mathrm{Pd}(\mathrm{TFA})_{2}$ / 2-hydroxymethylpyridine / $\mathrm{K}_{2} \mathrm{CO}_{3}$ has been shown to afford excellent catalytic activities for the arylation of structurally diverse allylic alcohols with arenediazonium salts to yield the expected arylated derivatives. From a practical point of view, this system offers several advantages because it involves simple starting materials, widely available pyridine-based ligands and tolerates the presence of a wide range of diazonium salts. Furthermore, our contribution concerns a stable "one-pot" ready-to-use metal-ligand catalyst precursor which does not need to operate under inert atmosphere and does not need laborious experimental procedures. This simple one pot catalytic system includes common pyridine-based ligands capable of playing the role of a potential chiral vector which provide great possibilities for an asymmetric version of this reaction, an almost unexplored area of research to date. Further research in this area is now in progress.

\section{Acknowledgements}

We are grateful to The "Centre National de la Recherche Scientifique" (CNRS), the University of Nantes and the "Institut Universitaire de France" (IUF) for financial support. The authors gratefully acknowledge Pavel S. Postnikov for fruitful discussions. Isabelle Louvet (CEISAM, University of Nantes), Denis Loquet (CEISAM, University of Nantes) and Julie Hémez (CEISAM, University of Nantes) are acknowledged for GC and GC-MS analyses.

\section{References}

1. R. F. Heck and J. P. Nolley, J. Org. Chem., 1972, 37, 2320-2322.

2. X.-F. Wu, P. Anbarasan, H. Neumann and M. Beller, Angew. Chem. Int. Ed., 2010, 49, 9047-9050.

3. K. Kikukawa and T. Matsuda, Chem. Lett., 1977, 6, 159-162.

4. $\quad$ P. Prediger, L. F. Barbosa, Y. Génisson and C. R. D. Correia, J. Org. Chem., 2011, 76, 7737-7749.

5. M. Raduán, J. Padrosa, A. Pla-Quintana, T. Parella and A. Roglans, Adv. Synth. Catal., 2011, 353, 20032012.

6. J. Salabert, R. M. Sebastián, A. Vallribera, A. Roglans and C. Nájera, Tetrahedron, 2011, 67, 8659-8664.

7. $\quad$ E. W. Werner and M. S. Sigman, J. Am. Chem. Soc., 2011, 133, 9692-9695.

8. I. Peñafiel, I. M. Pastor and M. Yus, Eur. J. Org. Chem., 2012, DOI: 10.1002/ejoc.201200181, 3151-3156.

9. C. C. Oliveira, E. A. F. dos Santos, J. H. B. Nunes and C. R. D. Correia, J. Org. Chem., 2012, 77, 81828190.

10. J. Salabert, R. M. Sebastián, A. Vallribera, J. F. Cívicos and C. Nájera, Tetrahedron, 2013, 69, 2655-2659.

11. V. Saini, L. Liao, Q. Wang, R. Jana and M. S. Sigman, Org. Lett., 2013, 15, 5008-5011.

12. B. Schmidt, N. Elizarov, R. Berger and M. H. Petersen, Synthesis, 2013, 45, 1174-1180.

13. B. Schmidt, N. Elizarov, R. Berger and F. Holter, Org. Biomol. Chem., 2013, 11, 3674-3691.

14. F.-X. Felpin, K. Miqueu, J.-M. Sotiropoulos, E. Fouquet, O. Ibarguren and J. Laudien, Chem. Eur. J., 2010, 16, 5191-5204.

15. N. Oger, E. L. Grognec and F.-X. Felpin, Curr. Org. Chem., 2015, 19, 695-707.

16. F. L. Callonnec, E. Fouquet and F.-X. Felpin, Org. Lett., 2011, 13, 2646-2649.

17. K. V. Kutonova, M. E. Trusova, A. V. Stankevich, P. S. Postnikov and V. D. Filimonov, Beilstein Journal of Organic Chemistry, 2015, 11, 358-362.

18. A. Roglans, A. Pla-Quintana and M. Moreno-Mañas, Chem. Rev., 2006, 106, 4622-4643.

19. P. Baumeister, W. Meyer, K. Oertle, G. Seifert and H. Steiner, Chimia, 1997, 51, 144-146.

20. V. D. Filimonov, M. Trusova, P. Postnikov, E. A. Krasnokutskaya, Y. M. Lee, H. Y. Hwang, H. Kim and K.-W. Chi, Org. Lett., 2008, 10, 3961-3964.

21. C. Molinaro, J. Mowat, F. Gosselin, P. D. O'Shea, J.-F. Marcoux, R. Angelaud and I. W. Davies, J. Org. Chem., 2007, 72, 1856-1858.

22. K. V. Kutonova, M. E. Trusova, P. S. Postnikov, V. D. Filimonov and J. Parello, Synthesis, 2013, 45, 27062710.

23. J. G. Taylor, A. V. Moro and C. R. D. Correia, Eur. J. Org. Chem., 2011, DOI: 10.1002/ejoc.201001620, 1403-1428.

24. F.-X. Felpin, L. Nassar-Hardy, F. Le Callonnec and E. Fouquet, Tetrahedron, 2011, 67, 2815-2831.

25. A. B. Dounay and L. E. Overman, Chem. Rev., 2003, 103, 2945-2964.

26. S. Yasui, M. Fujii, C. Kawano, Y. Nishimura and A. Ohno, Tetrahedron Lett., 1991, 32, 5601-5604.

27. M. Dai, B. Liang, C. Wang, J. Chen and Z. Yang, Org. Lett., 2004, 6, 221-224.

28. M. B. Andrus and C. Song, Org. Lett., 2001, 3, 3761-3764. 
29. J. Masllorens, M. Moreno-Mañas, A. Pla-Quintana and A. Roglans, Org. Lett., 2003, 5, 1559-1561.

30. K. Selvakumar, A. Zapf, A. Spannenberg and M. Beller, Chem. Eur. J., 2002, 8, 3901-3906.

31. E. W. Werner, T.-S. Mei, A. J. Burckle and M. S. Sigman, Science, 2012, 338, 1455-1458.

32. C. C. Oliveira, R. A. Angnes and C. R. D. Correia, J. Org. Chem., 2013, 78, 4373-4385.

33. R. A. Angnes, J. M. Oliveira, C. C. Oliveira, N. C. Martins and C. R. D. Correia, Chem. Eur. J., 2014, 20, 13117-13121.

34. C. C. Oliveira, A. Pfaltz and C. R. D. Correia, Angew. Chem. Int. Ed., 2015, 54, 14036-14039.

35. S. Cacchi, G. Fabrizi, A. Goggiamani and A. Sferrazza, Synlett, 2009, 2009, 973-977.

36. Y. Onishi, Y. Nishimoto, M. Yasuda and A. Baba, Org. Lett., 2011, 13, 2762-2765.

37. S. Biswas, S. Maiti and U. Jana, Eur. J. Org. Chem., 2010, 2010, 2861-2866.

38. H. Wang, Y. Li, R. Zhang, K. Jin, D. Zhao and C. Duan, J. Org. Chem., 2012, 77, 4849-4853.

39. T. Miyoshi, T. Miyakawa, M. Ueda and O. Miyata, Angew. Chem. Int. Ed., 2011, 50, 928-931.

40. E. Bardez, I. Devol, B. Larrey and B. Valeur, J. Phys. Chem. B, 1997, 101, 7786-7793.

41. H. Shindo, J. L. Walter, C.S.C and R. J. Hooper, J. Inorg. Nucl. Chem., 1965, 27, 871-878.

42. C. Icsel, V. T. Yilmaz, F. Ari, E. Ulukaya and W. T. A. Harrison, Eur. J. Med. Chem., 2013, 60, $386-394$.

43. T. Gosavi, C. Wagner, H. Schmidt and D. Steinborn, J. Organomet. Chem., 2005, 690, 3229-3236.

44. C. Icsel, V. T. Yilmaz, A. Golcu, E. Ulukaya and O. Buyukgungor, Bioorg. Med. Chem. Lett., 2013, 23, 21172122.

45. S. Taubmann and H. G. Alt, J. Mol. Catal. A: Chem., 2008, 289, 49-56.

46. C. Capello, U. Fischer and K. Hungerbuhler, Green Chem., 2007, 9, 927-934.

47. D. Prat, J. Hayler and A. Wells, Green Chem., 2014, 16, 4546-4551. 